\title{
Improving Pronunciation of Adult ESL Students
}

John van Loon

This article describes a classroom technique for improving the pronunciation of adult ESL learners. The technique is based on using stress and pausing in the same manner as native speakers of English. Dramatic improvement in pronunciation may be quickly achieved by showing learners how stress and pause are related to parts of speech and sentence structure. The article describes how a classroom teacher can develop an awareness of the relationship between grammar and pronunciation for learners.

Dans cet article, l'auteur décrit une technique pédagogique visant l'amélioration de la prononciation d'étudiants adultes ALS. Il s'agit d'une méthode où les étudiants emploient l'accent tonique et les pauses comme le font les anglophones. En expliquant aux étudiants les liens entre l'accent tonique et les pauses d'une part, et la nature grammaticale et la structure syntaxique d'autre part, l'enseignant constate des progrès très importants dans leur prononciation. L'article décrit la façon dont un enseignant peut conscientiser ses étudiants quant au rapport entre la grammaire et la prononciation.

\section{The Problem}

When an ESL student's pronunciation gets in the way of being able to communicate with other students in the class, I know there is a problem that needs remediation. Teaching clear pronunciation as a language skill can be frustrating. Hours of practice in the language lab or doing drills often yield minimal improvement. It has been my experience that more pronunciation drills do not improve how well a student speaks and is understood. While doing research on speech pauses I read an article on the importance of prosodic variables to the pronunciation ratings by native English speakers of non-native speakers (Anderson-Hsieh, Johnson, \& Koehler, 1992). I thought it might be worthwhile trying to put some of their findings on the importance of aspects such as stress and pause into practice. The technique I subsequently developed focuses on showing ESL learners the importance of using a native-like pattern of stress and pause in their speech, beginning with their oral reading. These prosodic features are easy for ESL learners to perceive and master. The technique is simple and dramatically improves the oral comprehensibility of adult ESL students. Best of all, it does not involve hours of pronunciation drill in a language lab. The technique takes ad- 
vantage of something most adult ESL learners have already been exposed to: lots of grammar. If your students can recognize clauses and parts of speech, you can convert this knowledge into speech that will be much more comprehensible. The technique I describe in this article is based on learners identifying nouns, verbs, and clause junctures before reading aloud. By placing stress on the nouns and verbs followed by pauses, as well as pauses at clause junctures, their pronunciation while reading aloud will become much more native-like.

\section{Background}

The perception of non-native pronunciation is strongly influenced by prosodic variables. Anderson-Hsieh et al. (1992) write that the prosodic variables of stress, rhythm, intonation, and pausing have the strongest effect on the pronunciation ratings of non-native speakers by native speakers. Pauses are relevant to ESL learners in other ways. Harley, Howard, and Hart (1995) note that stress and pause are two prosodic features of speech that can be of prime importance in second-language processing. Johnson and Moore (1997) show that there is a relationship between the reading proficiency of L2 learners and their ability to use native-like pausing in reading aloud. Among other aspects, research shows that pauses mark syntactic phrases (Cooper, 1980) and that a hierarchy of pause frequency and duration corresponds to a hierarchy of syntactic constituents (Grosjean, 1980). In a study of Chinese speakers of English, Anderson-Hsieh and Venkatagiri (1994) found near native-like proficiency in temporal variables such as pausing among more proficient speakers than among less proficient speakers. To Anderson-Hsieh and Venkatagiri this result suggests that the appropriate use of pausing is learnable.

Stress can be placed on a word by increasing the volume, changing the pitch, and/or lengthening the duration, and it is usually placed on nouns and verbs that are at the syntactic constituent boundaries, which as noted above are also the locations for pauses. Butcher (1981) groups pauses in three categories: unheard pauses of 100-200 milliseconds, short pauses of around 500 milliseconds, and long pauses of around 1,000 milliseconds. ESL learners often do not use pauses of any length-or they pause in the wrong locations. This contrasts with actors and trained speakers who increase pause duration for dramatic effect (O'Connell, 1988). Blau (1990) observes that when pauses of slightly longer duration are located at constituent boundaries, there is enhanced comprehensibility of aural input for second-language learners. I suspect that ESL teachers unconsciously increase pause duration when working with ESL learners because they notice that meaning is clearer to learners when they do so. For example, when giving instructions I have said: "Please stand up (extra pause), face the class (extra pause), and speak clearly." The evidence indicates a connection between stress and pauses at constituent 
boundaries and comprehensibility. By making this connection clear to my adult ESL learners, I have been able to improve their ability to make themselves understood.

\section{Audience}

The focus on stress and pause works particularly well with adult learners who are aware that it may not be possible to acquire native-like pronunciation, but at the same time know they need to improve the comprehensibility of their speech. Their inability to speak clearly interferes with their ability to interact with others in the English speech community. It also limits job opportunities. These learners are often highly motivated to learn, but are frustrated when they make little progress with their speaking abilities, especially when other non-native speakers do not understand them. Usually they are at the intermediate level and may have far better reading and writing skills than speaking skills.

\section{Teaching Materials}

The best materials to use in presenting the method are samples of students' speech that have been poorly understood by the other students in the class. These are the speech samples that pop up in class when students respond to questions or reading aloud. For example, a student might read:

When I woke (incorrect pause) up (no pause) I had a headache (no pause) and thought (too long a pause) I must have been (incorrect pause) sleeping on my arm.

Any speech samples from materials with which the students are currently working are useful to illustrate how stress and pause should be applied in their speech.

In my classes I often use news articles that the students bring to class. The best materials are those that are both authentic and relevant to the learners. A blackboard or overhead projector is useful to present the text under discussion to the entire class so that everyone can see which words are being stressed and where the pauses are located. I have also used overhead transparencies of spectrographs of utterances onto which I have transcribed the words. Such a transparency can give a dramatic representation of stress and pause in speech.

\section{Procedure}

I usually begin with a review of the parts of speech and emphasize the parts that usually carry the meaning, that is, the nouns and verbs. Then I reinforce the idea that a word carrying meaning is an important word and should therefore be stressed. I let the students know that for a word to be stressed, it should be immediately followed by a pause. Illustrate this principle in sen- 
tences by writing the sentence on the board with the stressed words written in capital letters and leaving a gap between the stressed word and the following word. An example would be:

The AGREEMENT would REQUIRE every COUNTRY to REDUCE its GREENHOUSE-GASES.

Read the sentence aloud in unison following the clues to stress and pause. The students can next practice with a sentence of their own that they write on the board for everyone to see as they read it aloud.

The next step is to work with sentences of more than one clause. Carefully read aloud complex and compound sentences to the students and have them identify the locations that mark the clause boundaries. An example would be:

PEOPLE are LEAVING two COMMUNITIES in ALBERTA as the huge FIRE SPREADS.

It is a good idea to emphasize the pause duration so that the students are aware of how pauses mark these boundaries. Again, write the sentences on the board so that they can visualize stress and note the locations of the pauses. Let the students practice this by again selecting other sentences in which they mark the nouns and verbs as stressed words. Pause locations are noted after the stressed words and at clause boundaries. I often have the students select sentences from the news articles that they bring to class. After the students have marked their sentences with the clues to stress and pause, have them individually read aloud the sentences. Even at this point all the students will notice a significant improvement in the comprehensibility of their classmates' speech. On one occasion the class broke into spontaneous applause after one student read aloud clearly; previously no one had been able to understand him. The difference came after showing the student how to use stress and pause correctly.

Next I like to have the class work with a news article that I have retyped and cut up so that the individual sentences are on separate strips of paper. I number the strips in the correct order and have each student select one. The students then mark the sentences for stress and pause, look up words they do not know, and practice reading the sentence with the correct stress and pause. One by one the students read their sentences in the appropriate order to the whole class. During the first reading their classmates can ask questions about the meaning of words. Before a second reading I hand out a short quiz based on the information in the news story. After each sentence is read aloud I collect the slips of paper so that the only source of information for the quiz is the oral reading that the students give. After all the students have presented their sentences, I ask one to reread all the sentences, and we review the answers to the quiz. 
The concept of applying correct stress and pause can be quickly and easily presented to intermediate ESL students who have the usual grounding in English grammar. It is one way to make practical use of the study of grammar. With regular reinforcement of how stress and pause are mapped onto the grammatical structure of English, students' pronunciation will greatly improve.

\section{Conclusion}

Prosodic features of speech are important parts of pronunciation, and the correct use of stress and pause can make a marked improvement in the speech of intermediate ESL learners. Unlike practicing segment articulation where improvement is slow and almost imperceptible, I have found that the correct application of stress and pause are readily apparent. The students invariably show astonishment on their faces when they hear the difference in the pronunciation of their classmates. Many times I have observed what was previously incomprehensible suddenly become clear to everyone when appropriate stress and pause are placed in the texts that are being read aloud. By trying this technique with your students you may discover ample evidence for its effectiveness.

Information gap activities such as reading a news story can reinforce the importance of oral reading with native-like pronunciation. Similarly, having the students read aloud directions or instructions for a task that the class will be doing would be a meaningful and effective way for learners to practice the use of stress and pause in their pronunciation. Whatever the task, clear pronunciation is essential to successful communication. The correct use of stress and pause may make a difference that will be a pleasant surprise to teachers and learners. Although this technique focuses on pronunciation while reading aloud, the use of correct stress and pause during free speech is equally important. This technique may help students recognize how stress and pause can improve their pronunciation in all situations.

\section{The Author}

John van Loon has taught EFL in the Czech Republic, Taiwan, and Japan. He is currently working in Croatia at the University of Zagreb, Philosophical Faculty, Department of English where he is teaching methodology. His research interests are listening comprehension, learnercentered teaching, and the use of technology in language learning.

\section{References}

Anderson-Hsieh, J., Johnson R., \& Koehler, K. (1992). The relationship between native speaker judgments of non-native pronunciation and deviance in segmentals, prosody, and syllable structure. Language Learning, 42, 529-555.

Anderson-Hsieh, J., \& Venkatagiri, H. (1994). Syllable duration and pausing in the speech of Chinese ESL speakers. TESOL Quarterly 28, 807-812.

Blau, E. (1990). The effects of syntax, speech, and pauses on listening comprehension. TESOL

Quarterly 24,746-53. 
Butcher, A. (1981). Aspects of the speech pause: Phonetic correlates and communicative functions. Kiel, Germany: Universität Kiel (Arbeitsbericht Nr. 15 des Instituts für Phonetik).

Cooper, W.E. (1980). Syntactic-to-phonetic coding. In B. Butterworth (Ed.), Language production: Speech and talk (pp. 306-324). London: Academic Press.

Grosjean, F. (1980). Comparative studies of temporal variables in spoken and sign languages: A short review. In H.W. Dechert \& M. Raupach (Eds.), Temporal variables in speech (pp. 41-53). New York: Mouton.

Harley, B., Howard, J., \& Hart, D. (1995). Second language processing at different ages: Do younger learners pay more attention to prosodic cues to sentence structure. Language Learning 45, 43-71.

Johnson, R., \& Moore, R. (1997). A link between reading proficiency and native-like use of pausing in speaking. Applied Language Learning 8, 25-42.

O'Connell, D.C. (1988). Critical essays on language use and psychology. New York: Springer-Verlag. 